\title{
Anti-inflammatory and immune-enhancing effects of enzyme-treated royal jelly
}

\author{
Hyejung Gu${ }^{1} \cdot$ In-Bong Song ${ }^{1} \cdot$ Hye-Ju Han ${ }^{1} \cdot$ Na-Young Lee ${ }^{2} \cdot$ \\ Ji-Yun Cha $^{2} \cdot$ Yeon-Kyong Son ${ }^{2} \cdot$ Jungkee Kwon $^{1}$
}

Received: 27 November 2017/ Accepted: 26 January 2018/Published online: 12 February 2018

(C) The Korean Society for Applied Biological Chemistry 2018

\begin{abstract}
Royal jelly is produced by honeybees and has been shown to be various pharmacologically active. Enzyme-treated royal jelly (ERJ) is an allergen-free form of royal jelly that has been converted to shorter easy-toabsorb chain monomers. In this study, we investigated the anti-inflammatory and immunomodulatory effects of ERJ on macrophages and mice. We found that ERJ altered macrophage proliferation and was protective against lipopolysaccharide (LPS)-induced stress. The mice, fed ERJ for 4 weeks and stimulated LPS, significantly reduced levels of tumor necrosis factor-alpha, interleukins-1, 6, 10, 12 , and interferon gamma compared to control mice. ERJ significantly increased the proliferation of B-lymphocytes and T-lymphocytes, as well as the activity of natural killer cells in a dose-dependent manner. Therefore, our results indicate that ERJ has strong anti-inflammatory and immune-promoting activities and can be developed as a potential food material for prevention of inflammatory disease.
\end{abstract}

Keywords Anti-inflammation · Enzyme · Immunity · Royal jelly

Jungkee Kwon

jkwon@jbnu.ac.kr

1 Department of Laboratory Animal Medicine, College of Veterinary Medicine, Chonbuk National University, Iksan, Jeonbuk, Republic of Korea

2 R\&D Team, Food and Supplement Health Claims, Vitech, Jeonju, Jeonbuk, Republic of Korea

\section{Introduction}

The inflammatory response is a defense mechanism of the immune system designed to recover damaged body functions. Macrophages regulate the immune response and play an essential role in the immune system. Specifically, activated macrophages produce and secrete a variety of cytokines such as tumor necrosis factor-alpha (TNF- $\alpha$ ) and interleukin (IL)-1, 6, 10 [1]. The inflammatory response is regulated in part by the balance of these cytokines, and imbalances in this system can cause and exacerbate various disease processes [2].

Most of the currently available anti-inflammatory drugs function by inhibiting the synthesis of prostaglandins and can cause serious side effects. Therefore, many studies have been conducted to investigate natural extracts capable of enhancing anti-inflammatory effects without producing deleterious side effects, and various natural compounds capable of enhancing immune function have been identified [3, 4]. For example, the natural substance royal jelly has a long history of use in enhancing immune system function.

Royal jelly has been reported to have many functional effects such as anticancer, -oxidant, and -inflammatory effects $[5,6]$ because of various bioactive substances like (E)-10-hydroxydec-2-enoic acid (10-HAD). However, royal jelly contains allergen-inducing proteins (molecular weight $47-55 \mathrm{kDa}$ ) that must be eliminated for the substance to be useful.

In this study, we created a hydrolyzed form of royal jelly using our own protease enzyme treatment method. The objective of this study was to investigate the anti-inflammatory and immune-enhancing effects of enzyme-treated 
royal jelly (ERJ) relative to conventional non-enzymetreated royal jelly $(\mathrm{RJ})$.

\section{Materials and methods}

\section{Preparation of ERJ}

Freeze-dried RJ powder was supplied from Zhejiang Jiangshan Bee Enterprise Co., Ltd. (Jiangshan, China). Proteolytic enzymes, including endo-protease obtained from cultures of Bacillus licheniformis, exo-protease, and endo- and exo-protease obtained from cultures of Aspergillus oryzae, were purchased from Vision Biochem (Sungnam, Korea). The content of 10-HDA and total free amino acid was measured by HPLC analysis (Dionex Ultimate 3000) using a Zorbax Extend-C18 column or a cation ion exchange column, respectively.

\section{Macrophage cell viability assay and measurement of NO production}

Macrophages isolated from $\mathrm{BALB} / \mathrm{c}$ mice [7] were plated in 96 well plates for $4 \mathrm{~h}$ at $37{ }^{\circ} \mathrm{C}$ in a $5 \% \mathrm{CO}_{2}$ incubator. Cells were treated with various amounts of ERJ $(25,50$, $100 \mu \mathrm{g} / \mathrm{mL})$ or RJ ( $100 \mu \mathrm{g} / \mathrm{mL})$ for $24 \mathrm{~h}$. Cell viability was determined by 3-(4,5-dimethylthiazol-2-yl)-2,5-diphenyltetrazolium bromide (MTT) assay, and the level of NO production was measured using a commercial Griess reagent system using a kit from Sigma (Sydney, Australia), Promega (Madison, WI, USA) according to the manufacturer's instructions.

\section{Animal and experimental design}

Six-week-old male BALB/c mice $(n=10)$ were obtained from Damul Science (Daejeon, Korea). All animals had first week of adaptation. Animals were randomly divided into seven groups as follows: Normal (normal control), Control (LPS $20 \mathrm{mg} / \mathrm{kg}$, i.p., once), ERJ groups (LPS + each ERJ 50, 150, 300, and $500 \mathrm{mg} / \mathrm{kg}$ ), and RJ (LPS + $500 \mathrm{mg} / \mathrm{kg}$ ). All mice had free access to water and production food with samples. The food intake of each mouse was measured daily, and body weight for each mouse was measured weekly after the start of treatments. Mice were maintained in microisolator cages under pathogen-free conditions with a 12-h light/dark schedule. All animals were cared for in accordance with the Chonbuk National University institutional guidelines for the care and use of experimental animals.
Cytokine analyses of serum and macrophages

The mice fasted for $12 \mathrm{~h}$ on the last day of the experiment were killed by cervical dislocation. Then, macrophages and blood were collected. Blood was centrifuged at $3000 \mathrm{rpm}$ for $15 \mathrm{~min}$ to obtain serum. Serum samples were frozen at $-70{ }^{\circ} \mathrm{C}$ for further analysis. The cytokines IL- $1 \beta$, TNF- $\alpha$ (Abcam, Cambridge, MA, UK), IL-6 (Life Technologies, Gaithersburg, MD, USA), IL-10, IL-2, and Interferon gamma (IFN- $\gamma$ ) (Thermo Scientific, MA, USA) were measured using a microplate reader (Bio-Tek, Winooski, VT, USA) according to the manufacturer's instructions.

\section{Spleen cell viability}

The proliferation of spleen cells over time was performed using spleen cells obtained from normal mice [8]. The cells were treated with appropriate concentrations of ERJ or RJ and cultured for $24 \mathrm{~h}$ before MTT. The proliferation of spleen cells with mitogen was performed using spleen cells isolated from mice fed with ERJ or RJ for 4 weeks. The cells were treated with $5 \mu \mathrm{g} / \mathrm{mL}$ of concanavalin A (ConA) or $15 \mu \mathrm{g} / \mathrm{mL}$ of LPS and cultured for $24 \mathrm{~h}$ before MTT.

\section{NK cell activity}

NK cell cytotoxicity was quantified using a lactate dehydrogenase (LDH) cytotoxicity detection kit (Takara Bio, Tokyo, Japan) according to the manufacturer's instructions and as previously described [9]. For the in vitro test, spleen cells were treated as indicated and incubated for $24 \mathrm{~h}$. For in vivo experiments, spleen cells were isolated from male BALB/c mice fed ERJ or RJ for 4 weeks and plated in 96 well plates at $37{ }^{\circ} \mathrm{C}$ in a $5 \% \mathrm{CO}_{2}$ incubator.

\section{Statistical analysis}

All values were expressed as mean \pm standard error (SE). Statistical differences between experimental groups were assessed using Student's $t$ test for two groups. One-way analysis of variance (ANOVA) was used for comparison among more than two groups. $p$ values $<0.05$ were considered statistically significant [10].

\section{Results and discussion}

\section{Confirmation of ingredient content change after enzyme treatment}

10-HDA, one of the fatty acids, is known as an indicator substance for evaluating the freshness and quality of royal jelly [11]. Therefore, we examined whether the level of 
Table 1 Changes in 10-HDA and total free amino acid contents in ERJ

\begin{tabular}{llc}
\hline & RJ & \multicolumn{1}{l}{ ERJ } \\
\hline 10-HDA & $50.0 \pm 0.0$ & $51.0 \pm 0.1$ \\
Total free amino acid content $(\mathrm{g} / \mathrm{mg})$ & 5.72 & $83.89 \pm 2.44$ \\
\hline
\end{tabular}

$10-\mathrm{HAD}$ was changed by enzyme treatment. The enzyme treatment significantly increased the level of total free amino acids due to decomposition of small molecules of the polymers (Table 1). Nevertheless, the level of 10-HDA was not changed by the enzyme treatment (Table 1). Therefore, the enzymatic processing of RJ is expected to improve the absorption rate. Therefore, the enzymatic processing of $\mathrm{RJ}$ is expected to improve the absorption rate.

\section{Evaluation of ERJ on macrophage cytotoxicity}

Macrophages act as antigen presenting cells, regulate $\mathrm{T}$ cell responses [12], and act to remove abnormal cells. To accomplish these functions, macrophages secrete immune substances such as NO, TNF- $\alpha$, and other cytokines [13]. We first used MTT assay to investigate the effect of ERJ on macrophage cell viability (Fig. 1A). We found that cell viability of macrophages treated with ERJ increased in a dose-dependent manner.

Macrophages are activated in response to invading microorganisms and foreign antigens to produce NO [13]. However, excessive production of NO by activated macrophages can cause oxidative stress and inflammation leading to general tissue damage, and DNA mutations [14]. Thus, appropriate regulation of NO production is an important role of the immune system. Given the importance of NO regulation, we next evaluated the effect of ERJ on NO production in macrophages. We found that NO production was slightly increased in response to ERJ treatment; however, there was no significant difference between vehicle, RJ, and ERJ treatments (Fig. 1B). These results suggested that ERJ does not disrupt macrophage homeostasis, nor does it increase basal inflammatory stress.

\section{Cytokine production in macrophages and serum}

Cytokines that are overexpressed by inflammation cause various autoimmune diseases such as sepsis, Alzheimer's disease, and multiple sclerosis [2]. Therefore, regulating cytokine expression is important for preventing inflammatory disease. Among the cytokines produced by macrophages, TNF- $\alpha$ and IL- $1 \beta$ are produced during the inflammatory response [1]. The proinflammatory cytokines IFN- $\gamma$ and IL- 2 play an important role early in the immune response by stimulating NK cells [15]. IL-6 stimulates proliferation and differentiation of $\mathrm{T}$ cells and $\mathrm{B}$ cells [16]. Conversely, IL-10 is an immunosuppressive cytokine that weakens antigen presentation by macrophages and acts to achieve an appropriately balanced immune response [17]. These cytokines play an important role in initiating and propagating or controlling inflammation together.

Therefore, we investigated the effect of ERJ on the expression of immune factors in vivo. During the treatment with ERJ, we found that food intake and body weight increased slightly with time; however, because these changes did not differ significantly between groups (Tables 2,3), they were attributed to normal aging. Overall, the changes in levels of cytokines in cultured macrophages and serum were similar. The levels of cytokines present in the LPS-induced control group were significantly higher than that of vehicle-treated mice, confirming induction of an inflammatory response. On the other hand, the abundance of cytokines in mice treated with ERJ generally decreased in a dose-dependent manner, and the level of cytokines in mice treated with RJ was similar or higher compared with the same concentration of ERJ (Fig. 2).

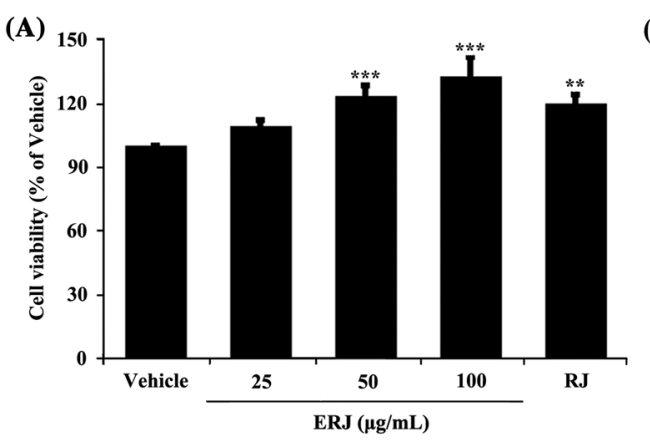

Fig. 1 Effect of ERJ on macrophage cell viability. (A) Cell viability of macrophages treated with ERJ for $24 \mathrm{~h}$. (B) Effect of ERJ on NO production in macrophages. ERJ enzyme-treated royal jelly, $R J$ non-

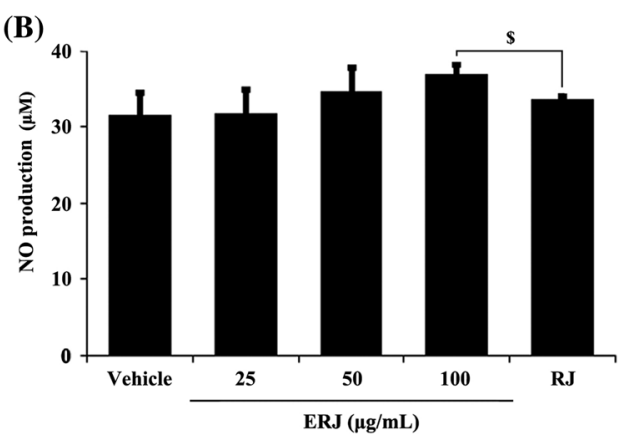

enzyme-treated royal jelly. Data are expressed as mean $\pm \mathrm{SE}$ $(n=3) . \quad * * p<0.01 ; \quad * * * p<0.001$, compared with vehicle. $\$_{p}<0.05$, compared with RJ 
Table 2 Changes in food intake in Balb/c mice fed ERJ for 4 weeks

\begin{tabular}{|c|c|c|c|c|}
\hline \multicolumn{5}{|c|}{ Food intake (g/day) } \\
\hline \multirow[t]{2}{*}{ Group (mg/kg) } & \multicolumn{4}{|l|}{ Week } \\
\hline & 1 & 2 & 3 & 4 \\
\hline Vehicle & $3.33 \pm 0.14$ & $3.89 \pm 0.30$ & $3.92 \pm 0.15$ & $4.07 \pm 0.08$ \\
\hline \multicolumn{5}{|l|}{ ERJ } \\
\hline 50 & $3.33 \pm 0.00$ & $3.83 \pm 0.14$ & $3.73 \pm 0.27$ & $4.00 \pm 0.40$ \\
\hline 150 & $3.19 \pm 0.31$ & $3.94 \pm 0.28$ & $3.93 \pm 0.20$ & $4.34 \pm 0.30$ \\
\hline 300 & $3.24 \pm 0.44$ & $3.89 \pm 0.46$ & $3.72 \pm 0.60$ & $4.16 \pm 0.56$ \\
\hline 500 & $3.14 \pm 0.27$ & $3.99 \pm 0.36$ & $3.58 \pm 0.09$ & $4.32 \pm 0.45$ \\
\hline RJ & $3.10 \pm 0.50$ & $3.88 \pm 0.33$ & $3.85 \pm 0.28$ & $4.37 \pm 0.11$ \\
\hline
\end{tabular}

Data are expressed as mean \pm SE $(n=10)$

$E R J$ enzyme-treated royal jelly, $R J$ non-enzyme-treated royal jelly

Table 3 Body weights of Balb/c mice fed ERJ for 4 weeks

\begin{tabular}{|c|c|c|c|c|c|c|}
\hline \multicolumn{7}{|l|}{ Body weight (g) } \\
\hline \multirow[t]{2}{*}{ Group (mg/kg) } & \multicolumn{5}{|l|}{ Week } & \multirow[t]{2}{*}{ Changes (g) } \\
\hline & 0 & 1 & 2 & 3 & 4 & \\
\hline Normal & $24.6 \pm 0.37$ & $25.56 \pm 0.45$ & $25.96 \pm 0.54$ & $26.22 \pm 0.79$ & $26.6 \pm 0.72$ & 2 \\
\hline \multicolumn{7}{|l|}{ ERJ } \\
\hline 50 & $23.87 \pm 0.72$ & $24.48 \pm 0.53$ & $25.02 \pm 0.64$ & $25.71 \pm 0.73$ & $25.77 \pm 0.55$ & 1.9 \\
\hline 150 & $23.65 \pm 0.73$ & $24.15 \pm 0.81$ & $24.69 \pm 0.72$ & $25.29 \pm 0.87$ & $25.66 \pm 0.71$ & 2.01 \\
\hline 300 & $23.93 \pm 0.41$ & $24.49 \pm 0.50$ & $25 \pm 0.61$ & $25.85 \pm 0.98$ & $25.87 \pm 0.73$ & 1.94 \\
\hline 500 & $24.08 \pm 0.64$ & $23.9 \pm 0.61$ & $24.77 \pm 0.83$ & $25.9 \pm 0.86$ & $26.10 \pm 0.25$ & 2.02 \\
\hline RJ & $23.08 \pm 0.61$ & $23.81 \pm 0.83$ & $24.25 \pm 0.89$ & $24.98 \pm 0.97$ & $25.14 \pm 1.18$ & 2.06 \\
\hline
\end{tabular}

Data are expressed as mean \pm SE $(n=10)$

$E R J$ enzyme-treated royal jelly, $R J$ non-enzyme-treated royal jelly, Changes changes in body weight in mice fed the indicated diet for 4 weeks

We found that overexpression of IL-2 and TNF was inhibited by ERJ in a similar manner. Likewise, ERJ decreased the expression of other cytokines in a dose-dependent manner (Fig. 2). IL-2 is secreted primarily from T helper 1 cells (Th1), while TNF- $\alpha$ is mainly secreted from macrophages during the early immune response. Secretion of other cytokines is in turn stimulated by IL- 2 and TNF- $\alpha$. These results suggest that ERJ has anti-inflammatory properties that are mediated through a direct effect on macrophages. Meanwhile, we found that ERJ increased the level of IL-10 expression in a similar manner to other cytokine factors. This result indicated that ERJ is effective not only in decreasing inflammation, but also maintaining immune system homeostasis. Our results suggest that ERJ might have a significant effect on inhibiting inflammation and improving immunity and might also be more effective than RJ at mediating these effects.

\section{Viability of immune-related cells}

The spleen is the primary lymphatic organ and plays a major role in the immune response. Maturation of $\mathrm{B}$ and $\mathrm{T}$ cells, associated with humoral and cell-mediated immunity, respectively, takes place in the spleen, as does antigenmediated differentiation of lymphocytes. In this way, proliferation and functioning of spleen cells are very important in the immune system, and the size and abundance of spleen cells can be used as indicators of the status of the immune system [18]. In the present study, we investigated the effect of ERJ on viability of B cells and T cells isolated from the spleen. Our results showed that ERJ and RJ increased the number of immune cells compared to vehicle in a dose-dependent manner (Fig. 3). 
(A)
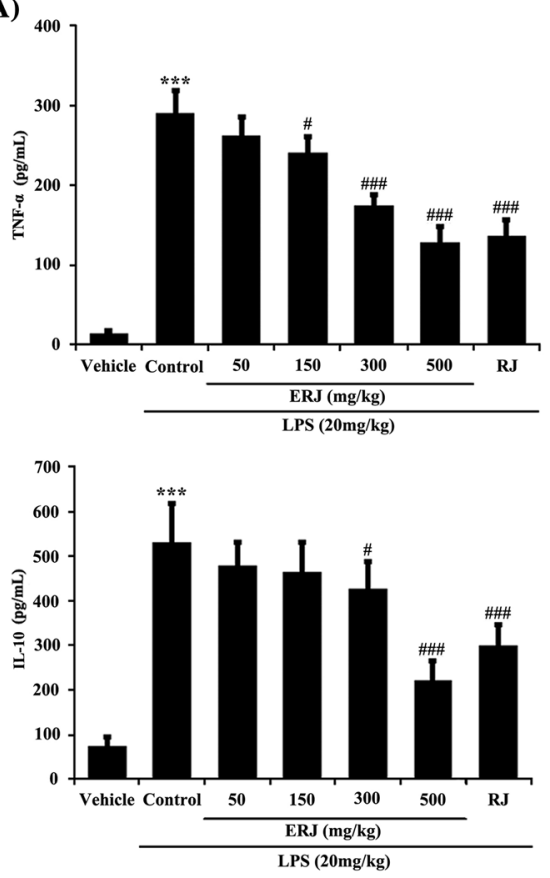

(B)
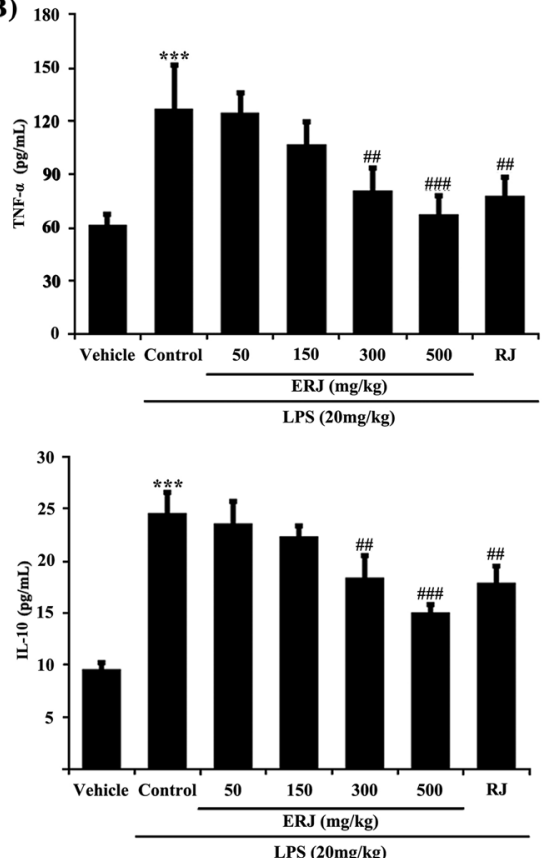


Fig. 2 Effect of ERJ on expression of inflammatory cytokines in serum and macrophages. (A) Expression of inflammatory cytokines in serum. (B) Expression of inflammatory cytokines in macrophages. $E R J$ enzyme-treated royal jelly, $R J$ non-enzyme-treated royal jelly.

\section{NK cell activity}

NK recognize abnormal cells and utilize cytotoxic molecules to induce death of their targets. During this process, NK cells utilize both activating and inhibitory signals to control cell-death activity [19]. NK cells are important during the initial immune stage. Therefore, we next
Data are expressed as mean $\pm \mathrm{SE}(n=10)$. *** $p<0.001$, compared with vehicle. ${ }^{\#} p<0.05 ;{ }^{\# \#} p<0.01 ;{ }^{\# \# p}<<0.001$, compared with control. ${ }^{\$} p<0.05 ;{ }^{\$} p<0.01$, compared with RJ

examined the effect of ERJ on NK-mediated immune response using LDH assays. Consistent with our results obtained thus far, treatment of NK cells with ERJ and RJ assays resulted in significantly higher NK cell compared to vehicle treatment both in vitro and in vivo, and these effects were dose-dependent for ERJ (Fig. 4). In addition, there was significant difference between the $100 \mu \mathrm{g} / \mathrm{mL}$ 


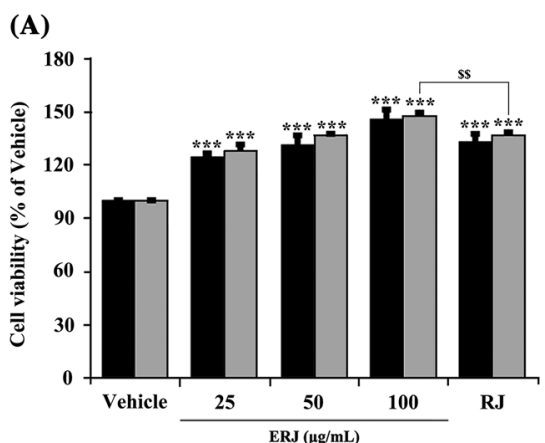

Fig. 3 Cell viability of immune cells treated with ERJ. (A) Viability of spleen cells treated with ERJ for 24 or $48 \mathrm{~h}$. ERJ enzyme-treated royal jelly, $R J$ non-enzyme-treated royal jelly. Data are expressed as mean $\pm \mathrm{SE}(n=3)$. (B) Cell viability of spleen cells treated with RJ

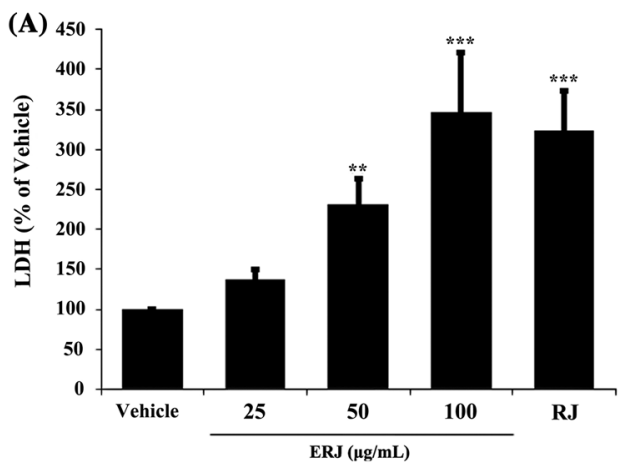

Fig. 4 Effect of ERJ on NK cell activity. (A) In vitro NK cell activity. ERJ enzyme-treated royal jelly, RJ non-enzyme-treated royal jelly. Data are expressed as mean $\pm \operatorname{SE}(n=3)$. (B) In vivo NK cell

ERJ and RJ treatment groups with respect to NK activity. Therefore, these results indicate that RJ itself has immuneenhancing effects with respect to NK cell activity that is not significantly different after enzyme treatment.

The results of the present study showed that ERJ has excellent anti-inflammatory properties and functions to improve immune responses. In addition, we found that ERJ inhibits the expression of inflammatory cytokines and improves immune function with respect to the activities of T cells, B cells, and NK cells. Together, these results suggest that ERJ could be useful as new substance for development as a functional food with potential immuneenhancing properties.

Acknowledgments This work (C0453904) was supported by the Business for Cooperative R\&D between Industry, Academy, and Research Institute funded by the Korea Small and Medium Business Administration in 2017.

\section{References}

1. Jeong JB, Hong SC, Jeong HJ, Koo JS (2012) Anti-inflammatory effects of ethyl acetate fraction from cnidium officinale Makino

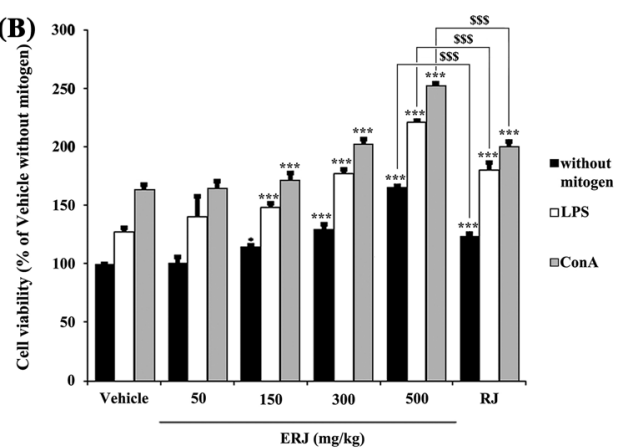

in the absence or presence of the indicated mitogens for $24 \mathrm{~h}$. ERJ enzyme-treated royal jelly, $R J$ non-enzyme-treated royal jelly. Data are expressed as mean $\pm \mathrm{SE}(n=10) * p<0.05$; ***p $<0.001$, compared with vehicle. ${ }^{\$ \$} p<0.001$, compared with RJ

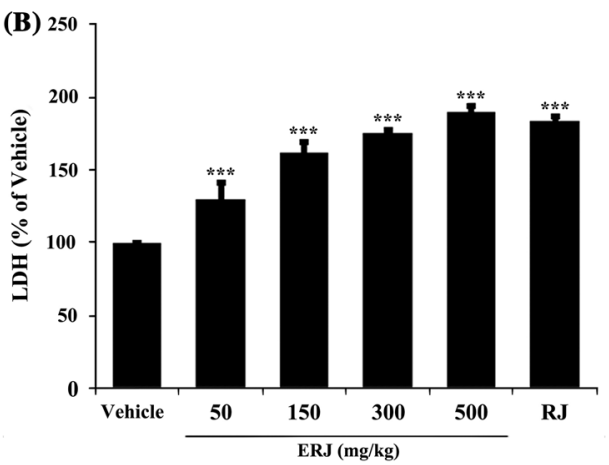

activity. $E R J$ enzyme-treated royal jelly, $R J$ non-enzyme-treated royal jelly. Data are expressed as mean $\pm \operatorname{SE}(n=10)$. $* * p<0.01$; $* * * p<0.001$, compared with vehicle

on LPS-stimulated RAW 264.7 and THP-1 cells. Korean J Plant Res 25:299-307

2. Moller B, Villiger PM (2006) Inhibition of IL-1, IL-6, and TNFalpha in immune-mediated inflammatory diseases. Springer Semin Immunopathol 27:391-408

3. Lee JS, Hong EK (2011) Immunostimulating activity of the polysaccharides isolated from Cordyceps militaris. Int Immunopharmacol 11:1226-1233

4. Yoo SA, Kim OK, Nam DE, Kim Y, Baek H, Jun W, Lee J (2014) Immunomodulatory effects of fermented Curcuma longa L. extracts on RAW 264.7 cells. J Korean Soc Food Sci Nutr 43:216-223

5. Guo H, Saiga A, Sato M, Miyazawa I, Shibata M, Takahata Y, Morimatsu F (2007) Royal jelly supplementation improves lipoprotein metabolism in human. J Nutr Sci Vitaminol 53:345-348

6. Kohno K, Okamoto I, Sano O, Arai N, Iwaki K, Ikeda M, Kurimoto M (2004) Royal jelly inhibits the production of proinflammatory cytokines by activated macrophages. Biosci Biotechnol Biochem 68:138-145

7. Seo MJ, Kang BW, Kim MJ, Lee HH, Seo KI, Kim KH, Jeong YK (2014) The effect of cordycepin on the production of proinflammatory cytokines in mouse peritoneal macrophages. Korean J Food Sci Technol 46:68-72

8. Ryu HS, Kim J, Kim HS (2006) Enhancing effect of Sorghum bicolor L. Moench (Sorghum, su-su) extracts on mouse spleen and macrophage cell activation. Korean Soc Food Nutr 19:176-182 
9. Kang IS, Kim RI, Kim GS, Kim NR, Shin JY, Kim C (2015) Effects of Agaricus blazei Murill water extract on immune response in BALB/c mice. J Korean Soc Food Sci Nutr 44:1629-1636

10. Andrikopoulos S, Blair AR, Deluca N, Fam BC, Proietto J (2008) Evaluating the glucose tolerance test in mice. Am J Physiol Endocrinol Metab 295:1323-1332

11. Townsend GF, Brown WH, Felauer EE, Townsend BH (1961) Studies on the in vitro antitumor activity of fatty acids: IV. The esters of acids closely related to 10-hydroxy-2-decenoic acid from royal jelly against transplantable mouse leukemia. Can J Biochem Physiol 39:1765-1770

12. Birk RW, Gratchev A, Hakiy N, Politz O, Schledzewski K, Guillot P, Orfanos CE, Goerdt S (2001) Alternative activation of antigen-presenting cells: concepts and clinical relevance. Hautarzt 52:193-200

13. Beutler B (2004) Innate immunity: an overview. Mol Immunol 40:845-859

14. Mu MM, Chakravortty D, Sugiyama T, Koide N, Takahashi K, Mori I, Yoshida T, Yokochi T (2001) The inhibitory action of quercetin on lipopolysaccharide-induced nitric oxide production in RAW 264.7 macrophage cells. J Endotoxin Res 7:431-438

15. Park SH, Kim MJ, Kim GE, Park SY, Kim KBWR, Kim YJ, Cho YJ, Ahn DH (2017) Immuno-enhancing effect of enzymatic extract of Sargassum coreanum using crude enzyme from Shewanella oneidensis PKA 1008. J Korean Soc Food Sci Nutr 46:919-928

16. Dienz O, Rincon M (2009) The effects of IL-6 on CD4 T cell responses. Clin Immunol 130(1):27-33

17. Fiorentino DF, Zlotnik A, Vieira P, Mosmann MTR, Howard KWM, O'Garra A (2017) IL-10 acts on the antigen-presenting cell to inhibit cytokine production by Th1 cells. J Immunol 146:3444-3451

18. Zalys R, Ian SZ, Robert HB, Lang CM, Patricia JM (2000) In vivo effects of chronic treatment with [Met5]-enkephalin on hematological values and natural killer cell activity in athymic mice. Life Sci 66:829-834

19. Vivier E, Tomasello E, Baratin M, Walzer T, Ugolini S (2008) Functions of natural killer cells. Nat Immunol 9:503-510 